\title{
INTOXICAÇÕES EM EQÜINOS NO BRASIL
}

\author{
INTOXICATIONS IN HORSES IN BRAZIL
}

\author{
Franklin Riet-Correa ${ }^{1}$ Mauro Pereira Soares ${ }^{2}$ Maria del Carmen Mendez
}

\section{- REVISÃo BIBLIOGRÁFICA -}

\section{RESUMO}

\begin{abstract}
Relatam-se algumas intoxicaçōes descritas em eqüídeos no Brasil. Dentre as intoxicações por plantas, incluem-se: Senecio spp., Ateleia glazioviana, Crotalaria juncea, Equisetum spp., Pteridium aquilinum, Baccharis coridifolia, Senna occidentalis e Brachiaria spp.. Mencionam-se, também, as micotoxicoses causadas por Fusarium moniliforme, Claviceps purpurea $e$ aflatoxinas, $e$ as intoxicações por uréia, iodo, chumbo e inseticidas clorados.
\end{abstract}

Palavras-chave: intoxicações em eqüinos, plantas tóxicas, micotoxinas, uréia, iodo, chumbo, inseticidas clorados.

\section{SUMMARY}

Toxic disease reported in horses in Brazil are reviewed. Intoxications by plants including: Senecio spp, Ateleia glazioviana, Crotalaria juncea, Equisetum spp., Pteridium aquilinum, Baccharis coridifolia, Senna occidentalis $e$ Brachiaria spp. are described. Mycotoxicosis caused by Fusarium moniliforme, Claviceps purpurea and aflatoxins, and intoxications by urea, iodine, lead, chlorinated insecticides are also mentioned.

Key words: horse intoxications, toxic plants, mycotoxins, urea, iodine, lead, chlorinated insecticides.

\section{INTRODUÇÃO}

O propósito deste trabalho é fazer uma revisão, necessariamente incompleta, sobre algumas intoxicações descritas em eqüinos nos diferentes Estados do Brasil.

\section{Intoxicação por Senecio spp.}

O primeiro surto da doença foi descrito em São Paulo em 1946, em eqüinos alimentados com alfafa contaminada por Senecio brasiliensis (CARVALHO \& MAUGE, 1946). Posteriormente, CURIAL \& GUIMARÃES (1958) relataram, no Paraná, 12 casos de cirrose hepática em cavalos associada, provavelmente, à ingestão de Senecio spp. Recentemente, foram descritos 4 surtos de intoxicação em Santa Catarina e um no Rio Grande do Sul (GAVA \& BARROS, 1997).

Nos casos de intoxicação natural, o primeiro sinal clínico observado é diminuição da ingestão de alimentos. Ocorre perda de peso, progressiva incoordenação motora, andar a esmo, tropeços e pressão da cabeça contra objetos, cegueira aparente, dificuldade de apreensão dos alimentos, disfagia e persistência da boca aberta. Outros sinais incluem edema subcutâneo no prepúcio e região ventral do abdômen, descarga nasal mucosa, sudorese, dor abdominal, prolapso de pênis e fotodermatite. Podese observar, também, opacidade de córnea, avermelhamento da esclera e conjuntiva de ambos os olhos e poliúria. O curso clínico varia de 3 a 60 dias, terminando em morte dos animais. Alguns eqüinos podem apresentar melhora temporária do quadro clínico (GAVA \& BARROS, 1997). Os sinais clínicos induzidos experimentalmente apresentam evolução de 1 a 6 dias, sendo caracterizados por anorexia, icterícia e distúrbios neurológicos, incluindo apatia,

\footnotetext{
'Médico veterinário, MSc., Laboratório Regional de Diagnóstico, Faculdade de Veterinária, Universidade Federal de Pelotas, $96010-$ 900, Pelotas, RS. Fax: 0532-759004. Email riet@ufpel.tche.br Autor para correspondência.

${ }^{2}$ Médico veterinário, MSc, Professor de Histologia da Faculdade de Veterinária da Universidade da Região da Campanha. Recebido para publicação em 14.01.98. Aprovado em 06.05.98
} 
sonolência, andar a esmo ou em círculos, incoordenação, pressão da cabeça contra objetos, contrações ou flacidez dos lábios, bocejos, dificuldade em deglutir e, nos estágios terminais, movimentos bruscos com a cabeça, reflexos palpebrais diminuídos ou ausentes e morte. Perda de peso é observada nos casos com curso mais longo (PILATI, 1990).

Experimentos com $\boldsymbol{S}$. brasiliensis em eqüinos reproduziram a intoxicação aguda com dose única de $1,74 \mathrm{~g}$ de planta seca por $\mathrm{kg}$ de peso vivo. A reprodução da intoxicação subaguda ocorreu com doses totais de $14,84 \mathrm{~g} / \mathrm{kg}$ administradas em 17 semanas e $19,32 \mathrm{~g} / \mathrm{kg}$ administradas em 82 dias (PILATI, 1990).

$\mathrm{Na}$ necropsia, o fígado apresenta fibrose, tumefação da superfície capsular e acentuação do padrão lobular. Pode haver ascite, edema e hemorragias no mesentério e nas paredes dos intestinos grosso e delgado. As lesões histológicas do fígado caraterizam-se por proliferação de tecido conjuntivo fibroso, megalocitose dos hepatócitos, proliferação de células dos ductos biliares, presença de nódulos regenerativos e diversos graus de degeneração e necrose de hepatócitos (PILATI, 1990; GAVA \& BARROS, 1997).

O diagnóstico é realizado pelos dados epidemiológicos e sinais clínicos, devendo ser confirmado pela presença das lesões histopatológicas características do fígado. É importante lembrar que a intoxicação por Senecio spp, é uma doença progressiva, onde os sinais clínicos podem ser observados várias semanas ou meses após a ingestão da planta. Portanto, é necessário determinar se houve ingestão de Senecio spp. no feno ou na pastagem, em um período de até 1 ano antes da observação dos sinais clínicos (PILATI 1990, GAVA \& BARROS, 1997).

\section{Intoxicação por Ateleia glazioviana.}

A árvore Ateleia glazioviana é encontrada freqüentemente na região Oeste de Santa Catarina e Noroeste do Rio Grande do Sul. Causa aborto em bovinos, ovinos, caprinos e eqüinos sendo, provavelmente, a principal causa de abortos em bovinos nessas regiões (STOLF et al., 1994). Os abortos geralmente ocorrem entre os meses de novembro e maio, devido à ingestão de folhas verdes das plantas em crescimento. Em algumas ocasiões, a intoxicação ocorre pelo consumo das folhas que caem no final do outono, e são ingeridas junto com a pastagem. Os abortos acontecem em qualquer fase da gestação e não ocorrem lesões específicas nos fetos (GAVA, 1993). A intoxicação é diagnosticada através da presença da planta e pelos resultados negativos a outras causas de aborto, principalmente ao Herpesvírus eqüino-1. Um surto dessa intoxicação, causando abortos em eqüinos, ocorreu no Município de São José do Ouro, Rio Grande do Sul, em maio de 1994 (BARROS, 1994. Comunicação pessoal).

A melhor forma de profilaxia da intoxicação é não colocar éguas prenhes em potreiros onde há a planta. Não é recomendado cortar as árvores, porque as brotações são mais facilmente ingeridas pelos animais. Pode-se erradicar a planta, utilizando herbicidas ou arrancando as árvores com as raízes (GAVA, 1993).

\section{Intoxicação por Crotalaria juncea}

Um surto dessa intoxicação ocorreu no município de Manga, Minas Gerais, afetando eqüinos adultos. Nessa propriedade, $\boldsymbol{C}$. juncea foi cultivada extensivamente para servir como fertilizante de solos esgotados e, devido ao bom desempenho da planta, e por sua alta concentração em proteínas, foi administrada aos animais. Vinte eqüinos receberam alimentação composta de $60 \%$ de milho e $40 \%$ de sementes de $\boldsymbol{C}$. juncea trituradas. Decorridos 30 a 60 dias, todos os animais apresentaram sintomatologia clínica de cambaleios, dispnéia e febre, culminando em morte. Os bovinos que receberam a mesma dieta não apresentaram sinais da intoxicação (NOBRE $\boldsymbol{e} t$ al., 1994).

Macroscopicamente, observa-se congestão, edema pulmonar, áreas difusas de consolidação do parênquima pulmonar e fígado aumentado de tamanho. $\mathrm{O}$ estudo histopatológico dos pulmões revela alveolite fibrosante difusa, com espessamento dos septos alveolares, formação de membrana hialina e epitelização alveolar. $O$ fígado apresenta-se congesto com espessamento dos sinusóides e compressão das trabéculas de hepatócitos, havendo também vacuolização citoplasmática. Os rins apresentam moderados graus de nefrose tubular, com vacuolização citoplasmática e descamação das células epiteliais (NOBRE et al., 1994). As plantas do gênero Crotalaria apresentam como princípio tóxico alcalóides pirrolizidínicos (NOBRE et al., 1994).

\section{intoxicação por Equisetum spp. e Pteridium aqui- linum}

Essas plantas têm sido descritas como tóxicas para eqüinos por conterem substâncias com efeito antitiamínico, causando um quadro de deficiência de tiamina (vitamina Bl) (ALVINCARNEIRO, 1948; DINIZ \& BASILE, 1984). A intoxicação por Equisetum spp. (cavalinha) foi diagnosticada no município de Catanduva, São Paulo, e no Triângulo Mineiro; neste último associada à ingestão de $\boldsymbol{E}$. giganteum. A ingestão ocorre no período da seca, devido a planta manter-se verde, ou pela ingestão de feno contaminado (ALVINCARNEIRO, 1948). 
Após algumas semanas de ingestão da planta, podem ser observados os primeiros sinais clínicos, caracterizados por perda de peso e sinais nervosos. Dependendo da idade do animal e da quantidade de planta ingerida, em aproximadamente 30 dias, observa-se perda do controle muscular e andar cambaleante. Posteriormente, o eqüino não consegue manter-se em pé, e a morte ocorre em consequiência do emagrecimento. (ALVINCARNEIRO, 1948).

A intoxicação por Pteridium aquilinum (samambaia) em eqüinos parece ser similar à intoxicação por Equisetum spp. Um surto da intoxicação por samambaia ocorreu no litoral do Paraná, afetando asininos que, após 60 dias do início do pastejo em áreas contaminadas, apresentaram anorexia, incoordenação dos membros posteriores e andar cambaleante. Em estação, os animais permaneciam com os quatro membros afastados ou com os anteriores cruzados e a cabeça apoiada em árvores ou barrancos. O curso clínico foi de aproximadamente 48 horas, morrendo 8 asininos de um total de 27. Após o tratamento com tiamina, alguns animais se recuperaram (DINIZ \& BASILE, 1984).

Em ambas as intoxicações não foram descritas alterações macroscópicas nem histológicas de significância. $\mathrm{O}$ tratamento indicado é a administração diária de $100 \mathrm{mg}$ de tiamina, porém, quando o animal está na fase final da doença, esse tratamento pode não ser eficiente (ALVIN-CARNEIRO, 1948; DINIZ \& BASILE, 1984).

\section{Intoxicação por Baccharis coridifolia}

Baccharis coridifolia (mio-mio) é uma planta conhecida na região da fronteira do Rio Grande do Sul, e pode ser encontrada em outras regiões do Estado, e nos Estados de Santa Catarina, Paraná e São Paulo. A intoxicação espontânea ocorre principalmente em bovinos e ovinos, porém há relatos de morte de eqüinos após a ingestão espontânea da planta (BARROS, 1993).

COSTA et al. (1995) administraram a planta fresca, coletada no outono, a eqüinos e estabeleceram como dose tóxica 0,125 a $0,5 \mathrm{~g}$ por $\mathrm{kg}$ de peso vivo. A intoxicação cursa com sinais digestivos agudos caraterizados por anorexia, hipertermia, dor abdominal, diarréia, desidratação, polidipsia, taquicardia, taquisfigmia, taquipnéia, dispnéia, inquietação e instabilidade locomotora. A morte ocorre 12 a 26 horas após a observação dos primeiros sinais clínicos. Na necropsia, observa-se congestão, edema, presença de fibrina e hemorragias petequiais no estômago e intestinos, principalmente no ceco e cólon. As alterações histológicas consistem de necrose da mucosa e edema da submucosa do ceco e cólon maior.
A intoxicação espontânea, geralmente, afeta animais que foram criados em áreas livres da planta e são transportados para áreas onde a planta está presente, e o risco da intoxicação aumenta se os animais transportados são submetidos à sede e à fome. A planta apresenta como princípio ativo micotoxinas do grupo dos tricotecenos, conhecidas como roridinas, e apresenta variação de toxicidade durante o ano, tendo maior toxicidade no outono, quando ocorre o florescimento (BARROS, 1993).

\section{Intoxicação por Senna occidentalis}

Senna occidentalis é uma leguminosa invasora de cultivos de verão, incluindo sorgo, milho e soja, e na colheita desses grãos pode haver contaminação por sementes da planta que, posteriormente, serão ingeridas junto à ração. A intoxicação tem sido diagnosticada em suínos em Santa Catarina (MARTINS et al., 1986) e em bovinos no Rio Grande do Sul (BARROS et al., 1990). No surto descrito no Rio Grande do Sul devido à ingestão de sorgo, há evidências de que eqüinos foram afetados (BARROS et al., 1990).

A dose tóxica de Senna occidentalis para equiinos corresponde a $0,3 \%$ e $0,15 \%$ do peso corporal, causando a morte em 4 a 96 horas após sua administração. Os sinais clínicos caraterizam-se por depressão, tremores musculares, ataxia, desequilíbrio, sudorese, respiração rápida e ofegante, taquicardia, dispnéia e relutância em mover-se. Há elevação sérica acentuada dos níveis de creatinina fosfoquinase (CPK), aspartato transaminase (AST) e gamaglutamil transferase (GGT). Macroscopicamente, observa-se nos músculos áreas esbranquiçadas ou amareladas, e fígado com aspecto de noz moscada. Histologicamente, há degeneração e necrose hepática acentuadas e necrose muscular segmentar. A planta apresenta efeito acumulativo (IRIGOYEN et al., 1991).

\section{Osteodistrofia fibrosa causada por Brachiaria spp.}

A osteodistrofia fibrosa de origem nutricional ocorre em consequiência do consumo de dietas ricas em fósforo e baixas em cálcio. Pode ocorrer, também, por dietas deficientes em Ca ou vitamina $\mathrm{D}$ e pela ingestão de oxalatos. $O$ desequilíbrio na relação $\mathrm{Ca}: \mathrm{P}$, onde o fósforo está em nível elevado, ocorre em animais que são alimentados com dietas ricas em grãos ou subprodutos de grãos, e que não são suplementados com $\mathrm{Ca}$. Devido à hiperfosfatemia, ocorre estímulo das paratireóides com hipersecreção de paratormônio, causando reabsorção óssea, para elevar a calcemia. Com o estímulo constante das paratireóides, o osso reabsorvido é substituído por tecido conjuntivo fibroso. 
A osteodistrofia fibrosa, geralmente, manifesta-se com aumento bilateral dos ossos da face, diminuição da resistência ao corte e substituição por tecido mole de aspecto gelatinoso e avermelhado, irregularidades nos cascos e má oclusão dentária, principalmente dos incisivos. Histologicamente, há rarefação óssea severa nos ossos faciais e de intensidade decrescente nas costelas, vértebras e nos ossos longos. As trabéculas ósseas são escassas e delgadas, revelando reabsorção profunda. Os osteócitos apresentam-se volumosos, com lacunas alargadas e circundados por matriz basófila (GUIMARÃES et al., 1984).

A ingestão de plantas, que contêm oxalatos, causa osteodistrofia fibrosa. Nesse caso, há uma deficiência de cálcio, por que o mesmo não está disponível para absorção, em consequiência de estar na forma de oxalato de cálcio, levando, também, à hipocalcemia e hiperparatireoidismo. Nas áreas de cerrado do Brasil Central, têm sido observados eqüinos com desenvolvimento retardado, baixo desempenho no trabalho, claudicações, emagrecimento e fratura de membros, em pastagens de Brachiaria humidicola, as quais contêm elevados níveis de oxalato e baixos níveis de cálcio (NUNES et al., 1990). Segundo LEMOS (1996. Comunicação pessoal), equiinos mantidos em pastagens de Brachiaria spp., na região do Mato Grosso apresentam tumefação dura dos ossos da face, claudicação, perda de peso e crescimento retardado. Devido à tumefação dos ossos da face, a doença na região é conhecida como cara inchada.

Intoxicação por milho contaminado com Fusarium moniliforme (LEUCOENCEFALOMALÁCIA)

A leucoencefalomalácia, doença causada pela ingestão de milho contaminado pelo fungo Fusarium moniliforme, foi primeiramente diagnosticada em 1949, no Estado de São Paulo (REGO CHAVES, 1950). Entre os anos de 1979 e 1996, pelo menos 94 surtos da doença foram diagnosticados no Brasil (RIET-CORREA et al., 1998). A doença já foi diagnosticada no Rio Grande do Sul (RIET-CORREA $\boldsymbol{e t}$ al., 1982; BARROS $\boldsymbol{e} \boldsymbol{t} \boldsymbol{a l}$., 1984), Paraná (HIROOKA et al., 1988; 1990), Santa Catarina (MARTINS et al., 1988; MEIRELES, 1993; RIET-CORREA et al., 1998), São Paulo (XAVIER et al., 1991; MEIRELES, 1993), Mato Grosso do Sul (LEMOS 1996. Comunicação pessoal), Minas Gerais (BRITO et al., 1982; MEIRELES, 1993; CARVALHO et al., 1995) e Goiás (CARVALHO et al., 1995).

Em amostras de milho provenientes de 21 surtos de leucoencefalomalácia, o percentual de umidade variou de $13,4 \%$ a $21 \%$, salientando-se que, em 5 amostras, a umidade estava dentro dos padrões exigidos no Brasil, de menos de $15 \%$ (MEIRELES, 1993). Os surtos têm ocorrido em animais que ingeriram milho moído, milho em espigas, rolão, e rações contendo milho (RIET-CORREA et al., 1998).

Os casos de leucoencefalomalácia são sazonais, ocorrendo, principalmente, entre os meses de junho e setembro, porém têm sido registrados surtos de março a dezembro (RIET-CORREA et al., 1998). $\mathrm{O}$ desenvolvimento de Fusarium moniliforme e suas toxinas está intimamente relacionado com a umidade e temperatura (HIROOKA et al., 1988, 1990; MEIRELES, 1993). O crescimento micelial ocorre mais facilmente entre 18 e $25^{\circ} \mathrm{C}$, porém a toxina só é produzida mediante choque térmico, com temperaturas situando-se entre 6 e $14^{\circ} \mathrm{C}$ (MEIRELES, 1993).

A taxa de morbidade em 28 surtos foi de $17,9 \%$ (16,8\% no Rio Grande do Sul e $18,2 \%$ no Paraná), variando de $4 \%$ a $100 \%$. A letalidade é de $100 \%$, afetando machos e fêmeas igualmente. Nos 94 surtos ocorridos no Brasil, morreram pelo menos 274 equídeos (CARVALHO et al., 1995; RIETCORREA et al., 1998).

Os sinais clínicos aparecem abruptamente e incluem anorexia, sonolência e depressão ou hiperexcitabilidade, dificuldade de apreensão de alimentos e mastigação, ataxia, tremores, pressão da cabeça contra objetos, torneios, cegueira uni ou bilateral e decúbito. O período de manifestação dos sinais clínicos varia de 2 a 72 horas, mas a maioria dos animais afetados morrem num período de 6 a 24 horas após o aparecimento da sintomatologia clínica (RIET-CORREA et al., 1982; BARROS et al., 1984; HIROOKA et al. 1988; 1990; MARTINS et al., 1988; MEIRELES, 1993). Em determinado surto, os animais morreram após um curso clínico de 1 a 7 dias (XAVIER et al., 1991). Em algumas ocasiões, os sinais clínicos apareceram até 12 dias após a retirada do milho da alimentação (RIET-CORREA, 1998).

As lesões macroscópicas do sistema nervoso central caracterizam-se por aumento de tamanho de um dos hemisférios cerebrais com amolecimento das circunvoluções. A superfície de corte fica amarelada com áreas de malácia no centrum semiovale e corona radiata dos hemisférios cerebrais. Cavidades contendo fluído são frequientemente observadas nestas áreas. A cápsula interna e o tálamo geralmente são afetadas. Áreas amareladas ou hemorrágicas são frequientemente observadas nos tubérculos quadrigêmeos, pedúnculos cerebelares, ponte e medula oblonga. As lesões são usualmente unilaterais, mas em algumas ocasiões são bilaterais, 
porém mais marcadas em um dos lados. As lesões macroscópicas são melhores observadas após fixação do sistema nervoso central em formalina a $10 \%$ a $25 \%$, mas as lesões liquefativas são facilmente observadas no cérebro fresco (BRITO $\boldsymbol{e t}$ al., 1982; RIET-CORREA et al., 1982; BARROS et al., 1984; HIROOKA et al., 1988; XAVIER et al., 1991; MEIRELES, 1993).

Histologicamente, observam-se áreas de malácia circundadas por edema e hemorragia da neurópila. Há tumefação de astrócitos nas áreas de malácia. Trocas degenerativas e hipertróficas no endotélio vascular, edema perivascular, hemorragias e glóbulos eosinofílicos também são observados. Alguns vasos apresentam manguitos perivasculares, consistindo de eosinófilos, neutrófilos ou células mononucleares (RIET-CORREA et al., 1982; BRITO et al., 1982; BARROS et al., 1984; HIROOKA et al., 1988; MEIRELES, 1993; XAVIER et al., 1991).

A micotoxina fumonisina, especialmente a B1, produzida pelo Fusarium moniliforme é a responsável pelo quadro clínico e patológico da intoxicação, sendo detectado níveis de $10 \mu \mathrm{g} / \mathrm{g}$ a $500 \mu \mathrm{g} / \mathrm{g}$ em $24(82,1 \%)$ das 32 amostras analisadas; (HIROOKA et al., 1988; MEIRELES, 1993). De 13 amostras de milho, coletadas no Paraná, onde havia ocorrido casos da doença, todas apresentaram fumonisina e $\boldsymbol{F}$. moniliforme. A fumonisina apresentou concentrações, variando entre 0,2 e $38,5 \mu \mathrm{g} / \mathrm{g}$ de fumonisina $\mathrm{B} 1$ e entre 0,1 e $12 \mu \mathrm{g} / \mathrm{g}$ de fumonisina B2, com concentração média de $11,9 \mu \mathrm{g} / \mathrm{g}$ e $4 \mu \mathrm{g} / \mathrm{g}$, respectivamente (SYDENHAM et al., 1992).

$\mathrm{O}$ diagnóstico da leucoencefalomalácia realiza-se considerando a ocorrência da enfermidade em fins de outono e inverno em eqüinos que ingeriram milho ou rações que contenham o grão, e pela presença de malácia na substância branca do encéfalo, alteração que não tem sido descrita em outras doenças de equiinos. Deve-se realizar o diagnóstico diferencial com a raiva, e a encefalomielite viral eqüina, sendo que esta última, contrariamente a leucoencefalomalácia, ocorre nos meses de verão. A única forma de prevenir eficientemente a doença é a de evitar, principalmente de maio a setembro, a administração de milho que não tenha sido submetido a um correto processo de secagem (RIETCORREA et al., 1982).

\section{Intoxicação por Claviceps purpurea}

A intoxicação ocorreu em dois haras de eqüinos Puro-Sangue Inglês, no município de $\mathrm{Ba}$ gé/RS, em éguas que estavam ingerindo aveia (Avena sativa) contaminada com azevém (Lolium multiflorum), que continha escleródios de Claviceps purpurea. Em um dos haras, a aveia continha $0,11 \%$ de escleródios e no outro $0,26 \%$. Nos dois haras, as éguas eram mantidas estabuladas durante a noite, ingerindo aproximadamente $4 \mathrm{~kg}$ de aveia, e passavam o dia em pastagens verdes de azevém e trevo branco (Trifolium repens) (RIET-CORREA et al. 1988).

Os sinais clínicos caracterizam-se pelo não desenvolvimento da glândula mamária e agalactia, que geralmente é permanente depois do parto. As éguas com agalactia apresentam liberação prematura da corioalantóide, e espessamento placentário, necessitando de rompimento manual da placenta. Algumas apresentam parto distócico, e em outras, a dilatação e as contrações estão diminuídas, sendo que após o parto as éguas permanecem fracas. Também ocorre retenção de placenta e ruptura uterina. Histologicamente, observa-se, na placenta, proliferação de tecido conjuntivo, causando engrossamento do alantocorion e membrana amniótica. Ocorrem áreas de calcificação no epitélio coriônico (RIETCORREA et al., 1988).

Os potros nascidos destas éguas apresentam debilidade, ausência de reflexo mamário e icterícia discreta, e, geralmente, morrem nos primeiros dias de vida. Nas necropsia, observa-se icterícia, fígado amarelado e aumentado de tamanho e hemorragias do baço e adrenal. Histologicamente, a lesão mais significativa é a severa vacuolização dos hepatócitos (RIET-CORREA et al., 1988).

A toxicidade dos escleródios de $C$. purpurea deve-se ao seu conteúdo em alcalóides denominados genericamente como ergoalcalóides. A profilaxia da intoxicação é realizada através da revisão visual dos grãos antes da sua utilização, para constatar a provável presença de escleródios de $\boldsymbol{C}$. purpurea. No caso de suspeita de contaminação de grãos moídos e rações, é necessário utilizar métodos químicos para detecção de $C$. purpurea. Apesar da intoxicação por $\boldsymbol{C}$. purpurea ser mais freqüente na alimentação com grãos, a doença pode ocorrer, também, em animais pastando gramíneas que estão sementando (RIET-CORREA et al., 1988).

\section{Aflatoxicose}

Um surto de aflatoxicose foi diagnosticado em um grupo de equiinos alojados em entidades hípicas de São Paulo. Os animais apresentaram sinais clínicos de inapetência, hipertermia, icterícia generalizada, hematúria, hemorragias petequiais nas conjuntivas e elevação dos níveis séricos de bilirrubina e desidrogenase láctica. De um total de 69 eqüinos, após um curso clínico de 2 a 5 dias, morreram 24 animais. Nas necropsias, foram observados edemas e hemorragias no tecido subcutâneo e sero- 
sas, aumento de tamanho do fígado, rim e baço e enterite necrótica aguda. As lesões histopatológicas caracterizaram-se por hepatite tóxica, enterite hemorrágica, nefrose e enterite necrótica. Os níveis das diferentes aflatoxinas na ração foram os seguintes: $\mathrm{B} 1=0,19 \mathrm{ppm} ; \quad \mathrm{B} 2=0,59 \mathrm{ppm}$.; $\quad \mathrm{G} 1=0,25 \mathrm{ppm} \quad$ e $\mathrm{G} 2=0,20 \mathrm{ppm}$, resultando uma concentração média de 0,30ppm (MACRUZ et al., 1986).

Segundo BORTEL et al. (1983), a dose tóxica experimental de aflatoxina B1 e M1 para pôneis é de $2 \mathrm{ppm}$, causando a morte dos animais após 76 horas da ingestão.

\section{Intoxicação por uréia}

A doença foi diagnosticada em eqüinos no ano de 1987, no município de Camaquiã, Rio Grande do Sul, em uma criação de cavalos da raça Crioula. Os animais estavam estabulados e cada um recebia diariamente $40 \mathrm{~kg}$ de azevém cortado e $7 \mathrm{~kg}$ de ração, contendo $70 \%$ de milho e $30 \%$ de soja. Um dia antes do aparecimento dos primeiros animais doentes, a pastagem de azevém havia recebido adubação nitrogenada, na dose de $30 \mathrm{~kg}$ por hectare (RIETCORREA et al., 1987).

De um total de 12 cavalos de diferentes idades, 10 foram afetados. Dos 3 primeiros animais doentes, dois estavam em coma e foram sacrificados. O terceiro animal apresentou severa depressão, incoordenação motora e alterações proprioceptivas da marcha; permaneceu doente durante vários dias, recuperando-se lentamente, sendo que 5 dias após o aparecimento dos primeiros sinais clínicos, ainda eram observados discreta incoordenação e alguns tremores localizados. Os demais animais apresentaram diversos graus de incoordenação motora e depressão. A recuperação, nesses animais, variou de 24 a 48 horas (RIET-CORREA et al., 1987).

Nas necropsias, não foram observadas lesões macroscópicas importantes. Ao exame histopatológico, observou-se, no fígado, congestão e vacuolização fina do citoplasma dos hepatócitos da região centrolobular e, no sistema nervoso central, discreta espongiose localizada principalmente na substância branca dos tubérculos quadrigêmeos e cápsula interna (RIET-CORREA et al., 1987).

As rações contendo farinha de soja, aumentam a liberação de amônia, pois a soja possui uma urease que facilita o desdobramento de uréia em amônia. A intoxicação pela uréia, ocorreu provavelmente devido à alta concentração de uréia no azevém e, talvez, pela combinação com a soja da ração, que facilitou a rápida liberação da amônia.

\section{Intoxicação por iodo}

A intoxicação foi diagnosticada em agosto de 1985, em um haras de PSI, no Rio Grande do Sul, no qual os potros foram suplementados com $700 \mathrm{mg}$ diários de iodo, e as éguas com $350 \mathrm{mg}$ diários, sendo a suplementação realizada mediante a administração de sal com $2 \%$ de iodeto de potássio (SILVA et al., 1987).

De 35 éguas prenhes, 17 abortaram e todos os potros abortados apresentaram as tireóides aumentadas de tamanho, estando maiores que um ovo de ganso. Um potro morreu imediatamente após o parto. Outros, com marcada debilidade e com as tireóides aumentadas, foram sacrificados. Outro potro foi sacrificado aos 3 meses de idade em conseqüência da fratura de um dos membros anteriores. Nas necropsias, os potros apresentaram marcada osteopetrose, principalmente dos ossos metacarpianos e metatarsianos, que apresentavam estreitamento da cavidade medular. Foi observado também alta incidência de claudicações, falha no fechamento da placa epifisiária e alterações nos aprumos. Após a retirada da suplementação com iodo, os potros nascidos 6 a 8 semanas após, não apresentaram bócio e estavam aparentemente normais (SILVA et al., 1987).

\section{Intoxicação por inseticidas clorados}

Relatam-se no Brasil, dois surtos de intoxicação causados por inseticidas clorados. Um surto ocorreu em pôneis causado pela ingestão de Aldrin (NAZARIO et al., 1972). O outro surto foi causado por Canfeclor (canfeno clorado) (NAZARIO \& CAPPELLARO, 1980).

A intoxicação por Aldrin, ocorreu em São Bernardo do Campo, São Paulo, onde eram criados pôneis para fins de recreação. $O$ envenenamento ocorreu de maneira intencional pela adição do inseticida à ração. Os animais tinham entre 7 e 15 anos, e morreram em intervalos mais ou menos regulares, totalizando 12 óbitos. O quadro clínico caracterizase por hipersensibilidade geral, às vezes com sinais de agressividade, ocorrendo também blefaroespasmos, fibrilação dos músculos cervicais, tremores dos membros anteriores e posteriores, sialorréia e sudorese abundante. A agitação dos animais torna-se crescente, seguindo-se por perda da coordenação dos movimentos. Posteriormente, passam a andar em círculos, caindo ao solo e permanecem em decúbito lateral, realizando violentos movimentos de pedaleio, acompanhados de fortes convulsões tônicoclônicas, sobrevindo a morte num prazo de 3 a 5 horas após o inicio dos sintomas. Os achados de necropsia consistem de hemorragias disseminadas que comprometem as vísceras abdominais, notadamente o estômago e intestinos. Os pulmões mostram-se isquêmicos, enfisematosos e com áreas de edema. Histologicamente, observa-se no pulmão, 
enfisema alveolar e edema alveolar e intersticial. Nos rins, observa-se congestão dos glomérulos e intensas hemorragias e edema intersticial. No cérebro, são vistas extensas áreas de necrose da substância branca, com acentuados focos de hemorragias e edema abrangendo, às vezes, também as meninges (NAZARIO et al., 1972). O diagnóstico da intoxicação foi confirmado pela análise químicotoxicológica da ração e do conteúdo estomacal dos animais, constatando-se concentrações de $0,3 \mathrm{ppm}$ de Aldrin (NAZARIO et al., 1972).

A intoxicação por Canfeclor aconteceu no Rio de Janeiro em uma caudelaria onde, de um total de 250 eqüinos estabulados, adoeceram 103 (41\%) e morreram $20(8 \%)$. Os animais estavam sendo alimentados com alfafa e apresentaram sintomatologia clínica 4 horas após a administração da alfafa. Os sinais da intoxicação foram caracterizados por excitação intensa, incoordenação motora, convulsões, dispnéia, e, em alguns casos, galope desenfreado, sendo que quatro animais morreram na fase sobreaguda da doença. Outros sinais observados foram congestão das mucosas, fasciculação muscular generalizada e contrações clônicas. Alguns animais apresentaram cegueira aparente, e decúbito lateral com movimentos de pedaleio. Nas necropsias foram observadas hemorragias musculares intensas, hemorragias petequiais no endocárdio, focos necrohemorrágicos no fígado, edema e hemorragias pulmonares. Histologicamente, a lesão mais importante foi a nefrose tóxica (NAZARIO \& CAPPELLARO, 1980).

Análises toxicológicas da alfafa efetuadas posteriormente, indicaram níveis de $8 \mathrm{~g}$ de canfeclor e $4,2 \mathrm{~g}$ de DDT por $\mathrm{kg}$ de alfafa (NAZARIO \& CAPPELLARO, 1980).

\section{Intoxicação por chumbo}

A intoxicação foi descrita no Vale do $\mathrm{Pa}$ raíba, São Paulo, em uma propriedade situada próxima a uma indústria de processamento e recuperação de chumbo industrial. A doença, provavelmente, aconteceu devido à inalação prolongada de vapores de chumbo e pela ingestão prolongada de pastagens contaminadas (MAZZEO et al., 1984).

Os sinais clínicos observados caracterizam-se por anorexia, dispnéia, bradicardia, emagrecimento, perda da acuidade visual, dificuldade motora com mảrcha trôpega, até a prostração em decúbito lateral permanente com movimentos incoordenados e contrações do tipo epileptiforme. Os animais apresentaram avidez pela água, apesar de manifestarem alguma dificuldade para deglutição. Descargas nasais muco-purulentas de cor esverdeada puderam também ser observadas. Após o $4^{\circ}$ ou $5^{\circ}$ dia, obser- vou-se diarréia com relaxamento do esfíncter anal. $O$ curso clínico da intoxicação variou de 8 a 30 dias. De um total de 36 equiinos morreram 20. Nas necropsias, observou-se coloração esverdeada ou acinzentada em áreas do pulmão, baço, fígado e mucosa lingual, secreção muco-purulenta nos brônquios, petéquias no pericárdio, e severa enterite e gastrite hemorrágica (MAZZEO et al., 1984).

O diagnóstico da intoxicação por chumbo é realizado através da determinação do nível deste elemento no sangue, o qual tem como nível normal $0,039 \mathrm{mg} / 100 \mathrm{ml}$ de sangue. No caso analisado, observou-se $0,067 \mathrm{mg}$ para cada $100 \mathrm{ml}$ de sangue (MAZZEO et al., 1984).

\section{COMUNICAÇÕES PESSOAIS}

BARROS, C.S.L. 1994. Comunicação pessoal. Departamento de Patologia da Universidade Federal de Santa Maria, 97119-900 Santa Maria, RS, Brasil.

LEMOS, R. 1996. Comunicação pessoal. Professor Assistente do Departamento de Medicina Veterinária da Universidade Federal do Mato Grosso, (UFMS), Campus Universitário, Caixa Postal 649, Campo Grande, MS, 79070-900. Fax (067) 787-5317

\section{REFERÊNCIAS BIBLIOGRÁFICAS}

ALVIN-CARNEIRO, P. Envenenamento por Equisetum sp. (Cavalinha). Ceres, v. 8, p. 32-36, 1948.

BARROS, C.S.L., PILATI, C.., ANDAJUR, M.B. et al. Intoxicação espontânea e experimental por Cassia occidentalis (Leg. Caes.) em bovinos. Pesq Vet Bras, v. 10, p. $47-58,1990$.

BARROS, C.S.L., BARROS, S.S., SANTOS, M.N. et al. Leucoencefalomalácia em eqüinos no Rio Grande do Sul. Pesq Vet Bras, v. 4, p. 101-107, 1984.

BARROS, C.S.L. Intoxicação por Baccharis coridifolia cap. 6, p. 159-169. In Riet-Correa, F., Méndez, M. C. \& Schild, A. L. (ed) Intoxicações por Plantas e Micotoxicoses em Animais Domésticos. Editorial Agropecuária Hemisfério Sur S.R.L., Buenos Aires. 340 p. 1993.

BORTEL, R., ASQUITH, R.L., EDDS, G.T. $\boldsymbol{e}$ t al. Acute experimentally induced aflatoxicosis in the weanling pony. Am J Vet Res, v. 44, p. $2110-2114,1983$

BRITO, A.B., NOGUEIRA, R.H.G., PEREIRA, J.J. et al. Leucoencefalomalácia em eqüino associada à ingestão de milho mofado. Arq Esc Vet UFMG v. 34, p. 49-53, 1982

CARVALHO, F.S.R., COELHO, H.E., RIBEIRO, S.M Micotoxicose em eqüino, causada pelo Fusarium moliniforme (Relato de Casos). Vet Notícias, v. 1, p. 37-43. 1995.

CARVAlHO, G.S.T., MAUGE, G.C. Ação tóxica do Senecio brasiliensis. Lessing Fam. Compositae. Rev da Fac Med São Paulo, v. 3, p. 131-136, 1946

COSTA, E.R., COSTA, J.N., ARMIÉN, A.G. et al. Intoxicação por Baccharis coridifolia em cavalos. Pesq Vet Bras, v. 15 p. 19-26, 1995 
CURIAL, O., GUIMARÃES, J.P. Cirrose hepática enzoótica no cavalo. Memórias do Instituto Osvaldo Cruz, v. 56, p. 635653,1958

DINIZ, J.M.F., BASILE, J.R. Intoxicação natural de asininos por Pteridium aquilinum (1.) Kühn no Brasil. Arq Bras Med Vet Zoot, v. 36, p. 515-522, 1984

GAVA, A. Intoxicação por Ateleia glazioviana cap. 10, p. $222-$ 225. In Riet-Correa, F., Méndez, M. C. \& Schild, A. L. (ed) Intoxicações por plantas e micotoxicoses em animais domésticos. Editorial Agropecuária Hemisfério Sur S.R.L., Buenos Aires. 340 p., 1993.

GAVA, A., BARROS, C. S. L. Senecio spp. poisoning of horses in southern Brazil. Pesq Vet Bras, v. 17, p. 36-40, 1997.

GUIMARÃES, E.B., NUNES, V.A., CHQUILOFF, M.A.G. $\boldsymbol{e} t$ al. Osteodistrofia fibrosa generalizada em pôneis no estado de Minas Gerais. Arq Bras Med Vet Zoot, v. 3, p. 265-274 1984.

HIROOKA, E.Y., VIOTTI, N.M.A., SOARES, L.M.V. et al. Intoxicação em eqüinos por micotoxinas produzidas por Fusarium moniliforme no norte do Paraná. Semina, v. 9, p. $128-135,1988$

HIROOKA, E.Y., VIOTTI, N.M.A., MAROCHI, M.A. et al. Leucoencefalomalacia em eqüinos no norte do Paraná. Rev. Microbiol, v. 21, p. 223-227, 1990.

IRIGOYEN, L.F., GRAÇA, D. L., BARROS, C.S.L. Intoxicação experimental por Cassia occidentalis (Leg. Caes.) em eqüinos. Pesq Vet Bras, v. 11, p. 35-44, 1991.

MACRUZ, R, LENCI, O, SANTOS, M.V.H.R. et al. Intoxicações por aflatoxinas na ração de eqüinos. In: XX CONGRESSO NACIONAL DE MEDICINA VETERINÁRIA, 14 Cuiabá/MT, 1986. Anais... Cuiabá: 1986. Resumo, p. 139.

MARTINS, E., MARTINS, V.M.V., RIET-CORREA, F. et al. Intoxicação por Cassia occidentalis (Leguminosae) em suínos. Pesq Vet Bras, v. 6, p. 35-38, 1986.

MARTINS, V.M.V., MARTINS, E.; NEVES, D.S. et al.. Leucoencefalomalacia em eqüinos no Estado de Santa Catarina. In: Ciclo de atualização em medicina veterinária (CAMEV), 6 Lages/SC. Resumo, p. 37, 1988.

MAZZEO, R.Jr., CLOTILDE, E.M.P., CAPPELLARO, C.E.M. et al. Ocorrência de saturnismo em eqüinos no Estado de São Paulo. Biológico, v. 50, p. 115-117, 1984.

MEIRELES, M.C.A. Leucoencefalomálacia eqüina (LEME) no Brasil: aspectos epizootiológicos, microbiológicos e toxicológicos. São Paulo, SP. 160p. Tese (doutor) Curso de Pós-graduação em Microbiologia e Imunologia da Escola Paulista de Medicina, USP, 1993.
NAZARIO, W., CAPPELLARO, C.E.M. Intoxicação em eqüinos por canfecior (canfeno clorado). Biológico, v. 46, p. 191-204, 1980

NAZARIO, W., MACRUZ, R., PORTUGAL, M.A.S.C. $\boldsymbol{e}$ t al. Envenenamento intencional em pôneis pelo aldrin (inseticida clorado). Atual Vet, v. 1, p. 22-28, 1972.

NOBRE, D., DAGLI, M.L.Z., HARAGUCHI, M.. Crotalaria juncea intoxication in horses. Vet Human Toxicol, v. 36, p. $445-448,1994$

NUNES, S.L., SILVA, J.M., SCHENK, J.A.P. Problemas com cavalos em pastagens de humidicola. Com téc $\mathbf{n}^{\mathbf{0}} \mathbf{3 7}$, CNPGC, Embrapa, p 1-4. 1990.

PILATI C. Intoxicação experimental por Senecio brasiliensis (Compositae) em eqüinos. Santa Maria, RS. 94p. Tese Mestrado em Medicina Veterinária. 1990.

REGO CHAVES, L. Doença de sintomatologia nervosa causada por intoxicação pelo milho. Rev Mil Rem Vet, v. 10, p. 199217,1950 .

RIET-CORREA, F., MÉNDEZ, M.C., SCHILD, A.L. Intoxicação por uréia em equiinos. In: Doenças diagnosticadas no ano de 1987, Pelotas/RS: Editora da Universidade, 1987, p. 20.

RIET-CORREA, F., MEIRELES, M.C.A., SOARES, J.M. et al. Leucoencefalomalácia em eqüinos associada à ingestão de milho mofado. Pesq Vet Bras, v. 2, p. 27-30, 1982.

RIET-CORREA, F., MEIRELES, M.C.A., BARROS, C.S.L. $e t$ $a l$. . Equine Leucoencephalomalacia in Brazil. In: Garland, T \& Barr, C. (ed) Poisonous Plants and other Natural Toxicants. CAB International, Willingford, UK. In Press, 1998.

RIET-CORREA, F., MÉNDEZ, M.C., SCHILD, A.L, et al.. Agalactia, reproductive problems and neonatal mortality in horses associated with the ingestion of Claviceps purpurea. Aust Vet J, v. 65, p. 192-193, 1988.

SILVA, C.A.M., MERKT, H., BERGAMO, P.N.L. et al. Consequence of excess iodine supply in a Thoroughbred stud in Southern Brazil. J Reprod Fert Suppl, v. 35, p. 529-533. 1987.

STOLF, L., GAVA, A., VARASCHIN, M.S. et al. Aborto em bovinos pela ingestão de Ateleia glazioviana (Leg. Papilionoideae). Pesq Vet Bras, v. 14, p. 15-18, 1994.

SYDENHAM, E.W., MARASAS, W.F.O., SHEPHARD, G.S. $\boldsymbol{e} t$ al. Fumonisin concentration in brazilian feeds associated with field outbreaks of animal mycotoxicoses. Agric Food Chemist, v. 40, p. 994-997, 1992.

XAVIER, J.G., BRUNNER, C.H.M., SAKAMOTO, M. et al Equine leucoencephalomalacia: report of five cases. Braz J Vet Res Anim Sci, v. 28, p. 185-189, 1991. 